\title{
Epidemiology of Traumatic Dental Injuries in Children and Adolescents - A Review
}

\author{
Amitha M. Hegde ${ }^{1}$, Sonali Sodhi ${ }^{2}$ \\ 1, 2 Department of Paediatric and Preventive Dentistry, AB Shetty Memorial Institute of Dental Sciences, \\ (Deemed to Be University), Mangalore, Karnataka, India.
}

\section{ABSTRACT}

\section{BACKGROUND}

Every child is prone to traumatic injuries, the impact of these injuries is directly related to the intensity, force and direction from which the trauma is inflicted. Trauma to the oral cavity is rather more common in children and adolescents as compared to the adult population. Since dental trauma is unanticipated, instantaneous and accidental, it often needs immediate and emergency management, depending on the severity of the injury. Thus, it is tremendously important to understand the patterns of incidence, prevalence, aetiology and risk factors associated with traumatic dental injuries. This article aims to review the epidemiology, incidence, prevalence, aetiology, risk factors and current trends of traumatic dental injuries in children and adolescents. The aetiologic factors vary among countries and within different age groups. The risk of sustaining traumatic dental injuries is generally dependent on several elements like age, circumstance, geography, behaviour and culture. Changing lifestyle especially related to urbanisation has led to amplification in the prevalence of dental trauma. The emergence of new trends in the modern society has led to creation of newer patterns and risk factors for the same. Traumatic dental injuries are linked to biological, social, financial and psychological factors. This article provides an overview on the epidemiology of traumatic dental injuries. This topic is of public health importance. This review is important to understand the underlying risk factors in order to reduce the prevalence and incidence of dental trauma. Educating the public regarding this will reduce the incidence of dental trauma.

\section{KEY WORDS}

Dental Trauma, Aetiology, Risk Factors, Epidemiology, Prevalence, Prevention, Paediatric Dentistry.
Corresponding Author:

Dr. Sonali Sodhi,

Department of Paediatric and Preventive Dentistry,

$A B$ Shetty Memorial Institute of Dental Sciences, (Deemed to Be University), Mangalore - 575018, Karnataka, India.

E-mail: sonalisodhi1994@gmail.com

DOI: $10.14260 / \mathrm{jemds} / 2021 / 353$

How to Cite This Article:

Hegde AM, Sodhi S. Epidemiology of traumatic dental injuries in children and adolescents - a review. J Evolution Med Dent Sci 2021;10(22):1709-1714, DOI: $10.14260 /$ jemds $/ 2021 / 353$

Submission 23-01-2021,

Peer Review 04-04-2021,

Acceptance 10-04-2021,

Published 31-05-2021.

Copyright (C) 2021 Amitha M. Hegde et al. This is an open access article distributed under Creative Commons Attribution License [Attribution 4.0 International (CC BY 4.0)] 


\section{BACKGROUND}

Several dental conditions like dental caries, periodontal problems, and genetic disorders can compromise a child's dentition. One of the leading factors that contribute to this is traumatic dental injury (TDI). Any kind of injury to the hard or soft tissue in and around the oral cavity is known as dental trauma. Dental trauma has become one of the major dental problems faced by children and adolescents. It is more expensive and time consuming as compared to other traumatic injuries presented to the emergency hospital and clinics. $^{1}$

The treatment approach for a TDI depends on the child's compliance and parental attitude towards the treatment. The age of the child also plays a huge part in determining his / her ability to cooperate during the treatment. Along with that, it is a dentist's duty to identify and report suspicious injuries to the authorities, as a significant number of child abuse injuries occur in the oral cavity in the form of TDIs. ${ }^{2}$

In children, road traffic accidents are frequently linked with TDIs, which occur in a combination with facial fractures. Whereas, exclusive dental injuries are usually related to minor accidents like fall or contact with blunt objects, which majorly occur during play hours. ${ }^{3}$

Despite the preponderance associated with traumatic dental injuries (TDI), it can be noted that there is a lack of understanding and knowledge when it comes to the incidence, aetiology, preventive measures for these injuries. Therefore the situation demands development of appropriate educational and awareness programs, taking these adequate measures can help with slackening these rising numbers.

Educating the individuals who oversee and handle children and are thus likely to be at the accident site TDI, has been deemed necessary. ${ }^{4}$

Such educational programs and initiatives should highlight the necessity of prompt treatment for dental trauma. They should also incorporate methods of prevention, procedures and appropriate emergency management. ${ }^{5}$

This review is important to understand the underlying risk factors in order to reduce the prevalence and incidence of dental trauma.

\section{SPECIAL CONSIDERATIONS IN YOUNG PAEDIATRIC POPULATION}

Young children have immature bone, which has big trabecular spaces hence it is more resilient, pliable and flexible as compared to the mature bone. Thus, the supportive structure in primary dentition, which is immature bone, is more prone to injuries as compared to the permanent dentition. ${ }^{6}$

TDIs in primary dentition can cause harm to the succedaneous erupting tooth or the forming tooth germ. This can happen by -

1. Direct impact injury to the permanent tooth germ from the traumatic forces generated by the apex of the primary tooth.

2. Indirect injury to the permanent tooth germ due to the products of pulpal necrosis generated in the infected per apical area.
Dental trauma can lead to various repercussions, which are dependent on the stage of development and maturation of both, the primary and the permanent tooth germ. The direction and intensity of trauma also play an important role in determining the sequelae of TDIs.

The resultant anomalies due to the outcomes can span from hypo calcification of the enamel to interference in the growth of the permanent tooth bud. The most common anomalies seen in the permanent dentition comprise of white or yellow opacity, enamel hypoplasia, crown dilacerations, root angulation, arrest of root development and interruption in normal eruption.7,8

TDIs are intricate in nature because they not only affect the traumatised tooth but also, the surrounding supportive tissues, per apical tissues and the adjoining teeth as well. Thus, the treatment and management of these injuries is multifaceted. 6

Dental trauma in primary teeth can thus not only lead to tooth aberrations but along with that it can have several other significant implications in terms of medical, aesthetic and psychological outcomes. ${ }^{5}$

The oral and emotional health of a young patient is interconnected and thus a child's semblance when impaired by an oral injury, must be restored back promptly to relieve the consciousness due to it. Thus, the idea of looking different than other children due to a TDI can have psychological implications. ${ }^{9}$ The current scenario thus dictates the need for inauguration of safe environments and provision of prompt care for TDI prevention. In order to establish these goals, TDI prevention and treatment programs which highlight the possible risk factors is utmost important.10

It is important to understand that young children are not cognitively mature enough to cope up with trauma and invasive dental treatment. Painful and taxing treatment in early childhood can lead to induction of dental fear and anxiety in adult life. Thus, the goal should be to plan the treatment in such a way that it minimises the stress caused due to trauma and does not give rise to any more stresses during the treatment. 11,12

\section{INCIDENCE AND PREVALENCE}

The incidence of TDIs in children, falls within the range of 1 3 percent in the population. ${ }^{1}$ Many studies have demonstrated that childhood and adolescence account for most of the TDIs. It has been assessed that $71-92$ percent of all TDIs experienced in a lifespan take place before the age of 19 years. ${ }^{13,14,15}$

The risk of sustaining a TDI is generally dependent on several elements like age, circumstance, geography, behaviour and culture. ${ }^{16}$ The variance in the prevalence of TDI amongst different geographical regions further substantiates the fact that culture, sanitation, financial status, kind of activities and profession practiced and environmental factors such as fluoride content in water account for this dissimilarity.

Studies indicate that the prevalence rate of dental trauma in the America was found to be greater than that of Asia or Europe. The incidence of dental trauma amongst the teenage population ranged around $15-23 \%$ and $23-35 \%$ in America and Europe respectively. ${ }^{17}$ In the Asia and Africa, the 
corresponding prevalence rates were found to be in the range of 4 - $35 \%$ and 15 - $21 \%$ respectively. $18,19,20$

Some individuals are at a greater risk of experiencing recurrent dental trauma, suggesting that risk corresponds to lifestyle routine and behaviours. ${ }^{21}$ Studies have also shown that children who display behavioural problems and peer relationship issues encounter more dental trauma as compared to other children.22

Hyperactive children have been reported to experience greater number of TDIs as compared to non-hyperactive children. ${ }^{23} \mathrm{~A}$ few reports have shown that a greater number of children from the lower socioeconomic status sustain dental trauma as children from the higher socioeconomic group. ${ }^{24}$

Conversely, a study revealed that those children with a higher socioeconomic group were found to be more prone to dental trauma. Since the individuals from this part of the society have an elevated access to high risk conditions and unsound environments, this puts them at an increased risk for dental trauma. This is one possible explanation, along with this, mothers who are more cultivated in their professions are often abstracted due to work-related pressure, which in turn decreases time spent at home and care of children, thus making these children comparatively more unsheltered to the risk factors associated with dental trauma. ${ }^{25}$

In spite of the dissimilarities, the current scenario indicates that 33 percent of all preschool children and 25 percent of adolescents and adults encounter TDI at least one time throughout their lifespan. Since oral cavity comprises of roughly 1 percent of the entire body area, this can be regarded noteworthy. ${ }^{1,16}$

Dental injuries in the primary dentition have a rather stable prevalence rate of around 30 percent in the majority of the studies. When talking about the permanent dentition, nearly all the studies quote the prevalence rate of around 20 percent. ${ }^{1}$

\section{AETIOLOGY AND PREDISPOSING RISK FACTORS}

Age of the patient is interconnected to the aetiological factors and help in determination of risk associated with dental trauma. It is noteworthy that in case of infants and toddlers, falling is the most common aetiological factor, which can be attributed to the fact that newly walking children have lack of harmony and imbalance and thus are prone to falling accidents. ${ }^{17}$ when it comes to preschool children, the most common cause of oral injuries is falls. On the contrary, in case of school children, sports or hits by another individual is generally the cause. Assaults and traffic accidents are the most common causes of oral trauma is case of older children and adolescents.1,21,26

For both the primary and permanent dentition, in case of children, the patient's home has been constantly reported as the leading location for sustaining oral and dental trauma. Regardless of this, sport stadiums, playing fields and roads feature in the majority of the studies in fluctuating percentages; a few studies have also reported that roughly 20 percent of the dental trauma takes place in unspecified locations or where the patient could not recall. ${ }^{16}$

It has been reported that injuries to dentin / pulp are more likely to occur in children with younger mothers, this can be attributed to the fact that adolescents and young adults are probably less attentive with their children as compared to older mothers. Likewise, with their greater maturity to speculate risky circumstances, older mothers potentially feel more confident about caring for their children, thus decreasing the chances of dental trauma.

Studies have also revealed that households with four or less members are more likely to acquire dental trauma at the dentin / pulp level. This can be attributed to the fact that mothers of households with lesser children are generally more inclined towards their professions and thus their children will be more vulnerable to dental trauma. ${ }^{25}$

Multiple facets have surfaced with respect to acute dental trauma, strong interdependence have been showed with overjet and lip incompetence, weaker positive relationship has been associated with age and canine occlusion. ${ }^{24}$

Children with adequate lip closure are less prone to sustain dental trauma than children with insufficient lip closure. Along with preventive action offered by lip closure, adequate occlusal relation of the maxillary and mandibular teeth also helps in diminishing the impact influence of the trauma. $27,28,29,30$

Children with an amplified over jet (exceeding $3 \mathrm{~mm}$ ) have been deemed to be more prone to acquire dental trauma than their peers with a conventional over jet. Thus, when it comes to risk factors associated with dental trauma, over jet is one of the primary determinants.3,27,31

A notable surge in the prevalence of dental trauma has been associated with special needs children; this is because of the lack of motor coordination seen in this group of children. ${ }^{27}$

A noteworthy statistical interrelation has been shown between dental trauma and medical conditions, intellectual disabilities, visual and hearing disabilities. Also, there has been a surged predisposition of dental trauma in patients with multiple disabilities.

Children with multiple disabilities have shown to have a higher prevalence (14 percent) as compared to children with intellectual disabilities (13.1 percent) and cerebral palsy (12.2 percent). ${ }^{32}$

A correlation between weight and dental trauma has also been pointed out. It has been said that obese children, when compared to children with conventional weight, were more likely to sustain dental trauma, particularly in the anterior region. ${ }^{33}$

\section{Age and Sex}

In the course of the initial 10 years of life, there is higher tendency of sustaining oral and dental injuries. This tendency moderately minimises with age and is extremely low after the age of 30 . However, the frequency of non-oral trauma is the maximum in case of adolescents and young adults, this frequency stays roughly the same throughout life. $1,34,35$

The type and aetiology of dental trauma has been shown to depend on whether the child has primary, mixed or permanent dentition. In case of primary dentition, trauma is more likely to result in displacement of the tooth due to the relatively lesser mineralised underlying bone structure.

In the age group of 0 to 6 years, owing to the growing range of self-dependent motion and activity, there is a pronounced range of dental trauma linked with falls and collisions in primary teeth. However, in the age bracket of 7 to 15 years, 
accidents while playing, sports-based injuries account for the majority of the dental trauma. ${ }^{36,16,13}$

40 percent of the somatic injuries in case of preschool children comprise of head and facial non oral injuries. By the virtue of high prevalence of oral and dental injuries in the age group of 0 to 6 years, it accounts for 18 percent of the all the somatic injuries.

In community based sample for assessing TDIs in the preschool revealed that percent of the of the children sustained dental trauma and 8 percent of those cases were severe in nature and were involved exposure of pulp, displacement of tooth, discoloration, necrosis or loss of the tooth. ${ }^{24}$

Amongst the oral injuries, dental trauma has a higher rate of occurrence as compared to the soft tissue injuries. According to the epidemiological studies, amongst preschool children ( 0 - 6 years), the 2 to 3 year age group has been shown to sustain the maximum number of TDIs. This can be attributed to the fact that, at this age, children exercise independent motion and activity and their motor skills are still developing. ${ }^{11,12}$

Countless studies have documented that boys tend to encounter dental trauma more often that girls. ${ }^{1}$ The corresponding prevalence can be elucidated by the fact that behaviour wise, boys are less mature than girls and often physically more active and predisposed towards extensive outdoor activities. This is in contrast with a study conducted by Gracia-Godoy where it was revealed that girls sustained more dental trauma (50.6 percent) as compared to boys (48.7 percent). Thus, it was concluded there was no noteworthy dissimilarity between sex and dental trauma. ${ }^{24}$ Several other studies also displayed a surge in the number of cases of TDIs among girls, this can be attributed to the fact that there is a rise in the involvement and participation in sports and games that were previously practiced by solely boys. ${ }^{37,38}$

\section{PREVENTION AND AWARENESS}

Childcare should be done more cautiously and wisely so as to assess the possible risk factors and prevent the incidence of TDIs. In case of toddlers and pre-school age group, the risk of falling, which the primary causes of dental trauma should be aimed at being eliminated. Trauma due to indulgence in sports is the other leading risk factor.

In order to minimise the incidence of dental trauma in children during sports related activities, safety precautions like use of adequate athletic appliances like mouth guards should be used especially in case of contact sports. Also, creating awareness and educating these children and adolescents regarding TDIs and safety protocols should be pursued. $17,39,40$

In this age group, peculiar traits like dominance, violence, emotional instability and illogical thought process are seen. Hence, fights and violence also account for a substantial amount of dental trauma cases. Thus, social education at home and school is utmost important and a special attention should be paid towards it. This will help in inculcating a culture of respecting others and acquiring self-control.

Several studies have published that dental traumatic accidents tend to take place at home most of the times. This can be attributed to the fact that children and adolescents spend a notable amount of time at home. Thus, it is important to educate households with children to practice adequate safety measures. $17,41,42,43$

The paucity in knowledge about TDIs in lay people can be explained by the fact that acute dental trauma care is normally not incorporated in their education or in the first-aid textbooks. ${ }^{44,45}$

Several attempts have been made to expand dental trauma first aid knowledge in dental trauma. Awareness and educational programs can be conducted for the parents and children, in which information regarding the safety protocols, prevention and treatment of this highly prevalent condition.

Dispense of pamphlets, posters and hand-outs with first aid guidance can be done, this has been shown to be a successful method. Emergency telephone services pertaining to dental trauma are another lucrative method to provide knowledge and support to parents and children. However, an emergency service will have to be initiated and measures to promote the emergency telephone numbers will have to be undertaken. $1,46,47,48$

The fact that TDIs not just compromise the oral health and esthetics of the child, but also lead to psychological implications, makes it an important public health matter. This article provides an overview on the epidemiology of traumatic dental injuries. It is important to understand the special pediatric anatomic, developmental and psychosocial considerations in order to analyse the incidence, prevalence and risk factors and thereby prevent dental trauma. Increase of knowledge regarding the same in dentists and lay population will aid in more favorable figures.

\section{CONCLUSIONS}

Dental injuries and dental caries pose a major public health problem and can create not just physical but significant psychological impact on not only children and adolescents but their parents as well. With adequate preventive measures, the prevalence of dental trauma can be reduced. Hence, better understanding about the associated risk factors will aid in prevention of dental trauma. 49

Unfortunately, the public is unaware of the risk and does not have enough information to prevent dental caries and to avoid traumatic injuries to the teeth. On the contrary, health professionals, including dentists, underestimate the incidence of dental caries and dental trauma and concentrate on the treatment rather than prevention. Preventive measures and public awareness can significantly decrease the prevalence of TDIs.

Financial or other competing interests: None.

Disclosure forms provided by the authors are available with the full text of this article at jemds.com.

\section{REFERENCES}

[1] Andersson L. Epidemiology of traumatic dental injuries. J Endod 2013;39(Suppl 3):S2-S5.

[2] Slayton RL, Palmer EA. Introduction: epidemiology of traumatic dental injuries. In: Traumatic dental injuries 
in children. Cham: Springer 2020. https://doi.org/10.1007/978-3-030-25793-4_1

[3] Andreasen JO, Andreasen FM, Andersson L. Textbook and Color Atlas of traumatic injuries to the teeth. $4^{\text {th }}$ edn. Wiley-Blackwell Publication 2007.

[4] McIntyre JD, Lee JY, Trope M, et al. Effectiveness of dental trauma education for elementary school staff. Dent Traumatol 2008;24(2):146-50.

[5] Kahabuka FK, Plasschert A, van't Hof M. Prevalence of teeth with untreated dental trauma among nursery and primary school pupils in Dares Salaam, Tanzania. Dent Traumatol 2001;17(3):109-13.

[6] Colak I, Markovic D, Petrovic B, et al. A retrospective study of intrusive injuries in primary dentition. Dental Traumatology 2009;25(6):605-10.

[7] Bardellini E, Amadori F, Pasini S, et al. Dental anomalies in permanent teeth after trauma in primary dentition. Journal of Clinical Pediatric Dentistry 2017;41(1):5-9.

[8] Hargreaves KM, Berman LH. Cohen's Pathway of pulp. $10^{\text {th }}$ edn. Mosby Elsevier 2010.

[9] McDonald RE, Avery DR, Dean JA. Management of trauma to the teeth and supporting tissues. In: Dentistry for the child and adolescent. St. Louis (MO): Mosby 2004: p. 454503.

[10] Borges TS, Vargas-Ferreira F, Kramer PF, et al. Impact of traumatic dental injuries on oral health - related quality of life of preschool children: a systematic review and meta - analysis. PLoS One 2017;12(2):e0172235.

[11] Malmgren B, Andreasen JO, Flores MT, et al. International Association of Dental Traumatology guidelines for the management of traumatic dental injuries: 3. Injuries in the primary dentition. Dental Traumatology 2012;28(3):174-82.

[12] Lauridsen E, Blanche P, Amaloo C, et al. The risk of healing complications in primary teeth with concussion or subluxation injury-a retrospective cohort study. Dental Traumatology 2017;33(5):337-44.

[13] Díaz JA, Bustos L, Brandt AC et al. Dental injuries among children and adolescence aged 1 - 15 years attending to public hospital in Temuco, Chile. Dent Traumatol 2010;26(3):254-61.

[14] Glendor U, Halling A, Andersson L, et al. Incidence of traumatic tooth injuries in children and adolescents in the county of Västmanland, Sweden. Swed Dent 1996;20(12):15-28.

[15] Davis GT, Knott SC. Dental trauma in Australia. Aust Dent J 1984;29(4):217-21.

[16] Lam R, Abbott P, Lloyd C, et al. Dental trauma in an Australian rural centre. Dent Traumatol 2008;24(6):66370.

[17] Azami - Aghdash S, Azar FE, Azar FP, et al. Prevalence, etiology, and types of dental trauma in children and adolescents: systematic review and meta - analysis. Med J Islam Repub Iran 2015;29(4):234.

[18] Marcenes W, Alessi ON, Traebert J. Causes and prevalence of traumatic injuries to the permanent incisors of school children aged 12 years in Jaragua do Sul, Brazil. Int Dent J 2000;50(2):87-92.

[19] Soriano EP, Caldas AF Jr, Góes PSA. Risk factors related to traumatic dental injuries in Brazilian schoolchildren. Dent Traumatol 2004;20(5):246-50.
[20] Gupta S, Kumar-Jindal S, Bansal M, et al. Prevalence of traumatic dental injuries and role of incisal overjet and inadequate lip coverage as risk factors among 4 - 15 years old government school children in Baddi - Barotiwala area, Himachal Pradesh, India. Med Oral Patol Oral Cir Bucal 2011;16(7):e960-5.

[21] Glendor U. Aetiology and risk factors related to traumatic dental injuries-a review of the literature. Dent Traumatol 2009;25(1):19-31.

[22] Odoi R, Croucher R, Wong F, et al. The relationship between problem behavior and tramatic dental injury amongst children aged 7 - 15 years old. Community Dent Oral Epidermiol 2002;30(5):392-6.

[23] Lalloo R. Risk factors for major injuries to the face and teeth. Dental Traumatology 2003;19(1):12-4.

[24] Born CD, Jackson TH, Koroluk LD, et al. Traumatic dental injuries in preschool - age children: Prevalence and risk factors. Clinical and Experimental Dental Research 2019;5(2):151-9.

[25] Bonfadini I, Pereira JT, Knorst JK, et al. Maternal characteristics, home environment and other factors associated with traumatic dental injuries in preschool children. Dental Traumatology 2020;36(1):33-40.

[26] Guedes OA, de Alencar AHG, Lopes LG, et al. A retrospective study of traumatic dental injuries in a Brazilian Dental Urgency Service. Braz Dent J 2010;21(2):153-7.

[27] Kumar S, Dixit G. Prevalence and risk factors for traumatic dental injuries in adolescent children attending special needs schools in India: a comparative study. International Journal of Adolescent Medicine and Health 2016;29(5):/ j/ijamh.2017.29.issue-5/ijamh-2015-0114/ijamh-20150114.xml.

[28] Kahabuka FK, Mugonzibwa EA. Risk factors for injuries to maxillary permanent incisors and upper lip among school children in Dar es Salaam, Tanzania. Int J Paediatr Dent 2009;19(2):148-54.

[29] Belcheva AB, Indzhova KN, St. Stefanov R. II. Risk factors for crown fractures of permanent incisors in children from Plovdiv. Folia Med (Plovdiv) 2008;50(2):50-6.

[30] Jariven S. Incisal overjet and traumatic injuries to upper permanent incisors. A retrospective study. Acta Odontol Scand 1978;36(5):359-62.

[31] Francisco SS, Filho FJ, Pinheiro ET, et al. Prevalence of traumatic dental injuries and associated factors among Brazilian school children. Oral Health Prev Dent 2013;11(1):31-8.

[32] Al - Batayneh OB, Owais AI, Al-Saydali MO, et al. Traumatic dental injuries in children with special health care needs. Dental Traumatology 2017;33(4):269-75.

[33] Vijaykumar S, Shekhar MG, Vijaykumar R. Traumatic dental injuries and its relation to overweight among Indian school children living in an urban area. Journal of Clinical and Diagnostic Research 2013;7(11):2631-3.

[34] Eilert-Petersson E, Andersson L, Sorensen S. Traumatic oral vs. non - oral injuries. An epidemiological study during one year in a Swedish county. Swed Dent J 1997;21(1-2):55-68.

[35] Glendor U, Andersson L. Public health aspects of oral diseases and disorders: dental trauma. In: Pine C, Harris R, eds. Community Oral Health. London: Quintessence Publishing 2007: p. 203-11. 
[36] Zaleckiene V, Peciuliene V, Brukiene V, et al. Traumatic dental injuries: etiology, prevalence and possible outcomes. Stomatologija 2014;16(1):7-14.

[37] Garcia-Godoy F, Morbán-Laucer F, Corominas LR, et al. Traumatic dental injuries in schoolchildren from Santo Domingo. Community Dent Oral Epidemiol 1985;13(3):177-9.

[38] Rocha MJ, Cardoso M. Traumatized permanent teeth in Brazilian children assisted at the Federal University of Santa Catarina, Brazil. Dent Traumatol 2001;17(6):245-9.

[39] Labella CR, Smith BW, Sigurdsson A. Effect of mouthguards on dental injuries and concussions in college basketball. Med Sci Sports Exerc 2002;34(1):41-4.

[40] Winters Sr JE. Commentary: role of properly fitted mouthguards in prevention of sport - related concussion. J Athl Train 2001;36(3):339-41.

[41] Garcia-Godoy F, Sanchez R, Sanchez JR. Traumatic dental injuries in a sample of dominican schoolchildren. Community Dent Oral Epidemiol 1981;9(4):193-7.

[42] Onetto JE, Flores MT, Garbarino ML. Dental trauma in children and adolescents in Valparaiso, Chile. Endod Dent Traumatol 1994;10(5):223-7.

[43] Blinkhorn FA. The etiology of dento - alveolar injuries and factors influencing attendance for emergency care of adolescents in the north west of England. Endod Dent Traumatol 2000;16(4):162-5.

[44] Zadik Y. Oral trauma and dental emergency management recommendations of firstaid textbooks and manuals. Dent Traumatol 2007;23(5):304-6.

[45] Emerich K, Gazda E. Review of recommendations for the management of dental trauma presented in first - aid textbooks and manuals. Dent Traumatol 2010;26(3):2126.

[46] Al - Asfour A, Andersson L. The effect of a leaflet given to parents for first aid measures after tooth avulsion. Dent Traumatol 2008;24(5):515-21.

[47] Lieger O, Graf C, El-Maaytah M, et al. Impact of educational posters on the lay knowledge of school teachers regarding emergency management of dental injuries. Dent Traumatol 2009;25(4):406-12.

[48] Arikan V, Sonmez H. Knowledge of primary school teachers regarding traumatic dental injuries and their emergency management before and after receiving an informative leaflet. Dent Traumatol 2012;28(2):101-7.

[49] Bendgude V, Akkareddy B, Panse A, et al. Correlation between dental traumatic injuries and overjet among 11 to 17 years Indian girls with Angle's class I molar relation. J Contemp Dent Pract 2012;13(2):142-6. 